\title{
A Simple Method for TPMT and ITPA Genotyping Using Multiplex HRMA for Patients Treated with Thiopurine Drugs
}

\author{
Marzena Skrzypczak-Zielinska $^{1}$ Pawel Borun ${ }^{1}$ Anna Bartkowiak-Kaczmarek ${ }^{2}$. \\ Oliwia Zakerska-Banaszak ${ }^{1} \cdot$ Michal Walczak $^{1}$ • Agnieszka Dobrowolska ${ }^{3}$. \\ Mateusz Kurzawski $^{4}$ - Malgorzata Waszak ${ }^{5}$ - Daniel Lipinski ${ }^{6}$ Andrzej Plawski ${ }^{1}$. \\ Ryszard Slomski ${ }^{1,6}$
}

Published online: 15 June 2016

(c) The Author(s) 2016. This article is published with open access at Springerlink.com

\begin{abstract}
Thiopurine methyltransferase (TPMT) and inosine triphosphatase (ITPA) are crucial enzymes involved in the metabolism of thiopurine drugs: azathioprine and 6-mercaptopurine, used in the treatment of leukemia or inflammatory bowel diseases (IBD). The activity in these enzymes correlates with the genetic polymorphism of the TPMT and ITPA genes, respectively, which determines an individual reaction and dosing of thiopurines. Three main TPMT alleles: TPMT*2 (c.238G $>\mathrm{C}), T P M T * 3 A$ (c. $460 \mathrm{G}>\mathrm{A}, \quad$ c. $719 \mathrm{~A}>\mathrm{G})$ and $T P M T * 3 C \quad(\mathrm{c} .719 \mathrm{~A}>\mathrm{G})$ account for $80-95 \%$ of inherited TPMT deficiency in different populations in the world. In the ITPA gene, a c. $94 \mathrm{C}>\mathrm{A}$ mutation is significantly associated with an adverse thiopurine reaction. The aim of this study was to develop a quick and highly sensitive method for determining major TPMT and ITPA alleles. Here we present the molecular test for genotyping c. $238 \mathrm{G}>\mathrm{C}, \mathrm{c} .460 \mathrm{G}>\mathrm{A}, \mathrm{c} .719 \mathrm{~A}>\mathrm{G}$
\end{abstract}

Marzena Skrzypczak-Zielinska

mskrzypczakzielinska@gmail.com

1 Institute of Human Genetics, Polish Academy of Sciences, ul. Strzeszynska 32, 60-479 Poznan, Poland

2 Laboratory of Cell Biophysics, Nencki Institute of Experimental Biology, Polish Academy of Sciences, Warsaw, Poland

3 Department of Gastroenterology, Human Nutrition and Internal Diseases, University of Medical Sciences, Poznan, Poland

4 Department of Experimental and Clinical Pharmacology, Pomeranian Medical University, Szczecin, Poland

5 Department of Functional Anatomy, University School of Physical Education, Poznan, Poland

6 Department of Biochemistry and Biotechnology, University of Life Sciences, Poznan, Poland and c.94C $>\mathrm{A}$ changes based on multiplex high resolution melting analysis (HRMA). We analyzed DNA samples from 100 clinically diagnosed IBD patients treated with thiopurine drugs, and a known genotype in the positions 238,460 and 719 of the TPMT gene as well as in position 94 of the ITPA gene. Our results obtained with multiplex HRMA indicated $100 \%$ accuracy in comparison with data from restriction fragments length polymorphism (RFLP) and standard DNA sequencing. We conclude, that multiplex HRMA can be used as a quick, sensitive and efficient alternative diagnostic method compared to conventional techniques for the determination of $T P M T^{*} 2, T P M T^{*} 3 A$ and $T P M T^{*} 3 C$ alleles and c. $94 \mathrm{C}>\mathrm{A}$ change in the ITPA gene.

\section{Key Points}

The methodology described allows the simultaneous analysis of c.460G $>$ A, c.719A $>$ G and c. $238 \mathrm{G}>\mathrm{C}$ changes of the TPMT as well as c.94C $>\mathrm{A}$ of the ITPA gene by quick and economic multiplex HRMA.

The multiplex HRMA can be used as a sensitive and efficient alternative diagnostic method for the determination of $T P M T * 2, T P M T * 3$ and ITPA c. $94 \mathrm{C}>\mathrm{A}$ alleles.

\section{Introduction}

Thiopurine drugs, which include immunosuppressant azathioprine (AZA), anticancer agents 6-mercaptopurine (6MP) and 6-thioguanine (6TG), are currently widely used in the treatment of chronic inflammatory disorders as 
inflammatory bowel diseases (IBD), in hematological malignancies and in transplantation [1].

Peak plasma concentrations are reached after $1-2 \mathrm{~h}$ in most patients following oral intake. The thiopurine concentration then rapidly decline with half-lives of less than $1 \mathrm{~h}$ [2]. Particularly essential in the AZA biotransformation is thiopurine methyltransferase (TPMT, EC2.1.1.67). This enzyme catalyzes the S-methylation of thiopurines. An increased risk of adverse reactions from AZA and 6MP depends on accumulation of thioguanine nucleotide metabolites (6TGN). The concentration of 6TGN is inversely proportional to the activity of the TPMT enzyme and conditioned by the sequence variations in the thiopurine S-methyltransferase gene (TPMT, MIM 187680). Approximately 1 in 300 persons $(0.3 \%)$ has low or undetectable TPMT enzyme activity, whereas about $11 \%$ are heterozygous for TPMT gene mutations resulting in intermediate thiopurine methyltransferase activity [3]. Currently, 37 alleles responsible for TPMT deficiency $(T P M T * 2-38)$ are known [4]. However, three alleles: TPMT*2 (c.238G $>$ C, p.Ala80Pro, rs1800462 in the exon 4), TPMT*3A (a combination of c.G460A, p.Ala154Thr, rs 1800460 in the exon 6 with c.719A $>$ G, p.Tyr240Cys, rs1142345 in the exon 9) and $T P M T * 3 C($ c.719A $>$ G) are responsible for 80-95\% of inherited TPMT deficiency in different populations all over the world [5]. According to the Single Nucleotide Polymorphism Database (dbSNP, 1000 Genomes) the variants c. $460 \mathrm{G}>\mathrm{A}$, c. $719 \mathrm{~A}>\mathrm{G}$ and c. $283 \mathrm{G}>\mathrm{C}$ of the TPMT gene are reported with the global minor allele frequency of $1.28,3.91$ and $0.22 \%$, respectively. In pharmacogenetic testing, these mutations are mainly analyzed according to the guidelines developed by the Clinical Pharmacogenetics Implementation Consortium, which provides dosing recommendations (updates at http://www.pharmgkb.org) for AZA, mercaptopurine (MP) and thioguanine [6].

A second significant protein, involved in the biotransformation of thiopurine drugs is inosine triphosphatase (ITPA; EC3.6.1.19). This enzyme catalyzes the pyrophosphohydrolysis of inosine triphosphate (ITP) to inosine monophosphate (IMP) preventing the accumulation of potentially toxic ITPs, which can be incorporated into nucleic acids and lead to cell apoptosis [7]. The ITPase is encoded by the inosine triphosphatase gene (ITPA, MIM 147520). So far, two mutations resulting in reduced activity of the ITPase have been identified: p.P32T (c.94C $>$ A, rs1127354) and IVS2 + 21 A $>$ C (rs7270101). However, a stronger effect is caused by the exonic mutation (c.94C $>$ A). The homozygosity of the ITPA c.94A allele leads to a deficiency in the ITPase activity in erythrocytes and lymphocytes, this occurs in approximately 1 in 1000 Caucasians. Heterozygotes constitute about $6.0 \%$ of Caucasian populations, and have an average red cell ITPase activity of about $22 \%$ of the control mean value. This allele is more common in Asian populations, with a frequency of 14-19\% [8]. Furthermore, it was observed that the ITPA c.94C/A genotype makes a contribution to the concentration of 6-methylmercaptopurine (6MMP) in red blood cells and the occurrence of hepatotoxicity [9] as well as the survival rate in pediatric patients with acute lymphoblastic leukemia (ALL) $[9,10]$.

Therefore, based on clinical and pharmacogenetic studies, it is crucial to generate an efficient diagnostic tool for the determination of TPMT*2 and $* 3$ alleles and the c. $94 \mathrm{C}>\mathrm{A}$ change in the ITPA gene. At the same time, due to the development of new, high-throughput molecular genetic techniques, the aim is to replace the previous standard methods for mutation detection (e.g. RFLP, SSCP, DHPLC, Sanger sequencing), which are time-consuming, laborious, and expensive. Also, in the literature reporting TPMT gene analysis, the evolution and search for new methods of detecting variants can be observed.

Recently, in a few studies, descriptions of modern methods for TPMT alleles determination using real-time polymerase chain reaction (PCR) machines have been presented. This confirms the high prevalence of this type of equipment in laboratories [11-13] and it highlights the need for improvements in TPMT genotyping tests. We demonstrate and encourage the use of a more cost-effective application than specific reactions with labeled dyes like TaqMan or hybridization probes. Here we describe a quick, sensitive and cost-effective genotyping methodology using multiplex high resolution melting (HRM) analysis for identifying $T P M T * 2, T P M T * 3 A, T P M T * 3 C$ and ITPA c. $94 \mathrm{C}>\mathrm{A}$ alleles.

\section{Material and Methods}

\subsection{DNA Samples}

DNA was collected in the Institute of Human Genetics Polish Academy of Sciences in Poznan from 100 IBD patients, treated in the Department of Gastroenterology, Human Nutrition and Internal Diseases, Poznan University of Medical Sciences. Furthermore, two control DNA samples $(T P M T * 1 / * 2$ and $T P M T * 3 A / * 3 A$ alleles) from the Department of Experimental and Clinical Pharmacology at the Pomeranian Medical University in Szczecin (Poland) were used for validation of the multiplex HRMA. These patients had already been tested for $T P M T * 2, T P M T * 3 A$, TPMT*3C and ITPA c. $94 \mathrm{C}>\mathrm{A}$ alleles by the standard restriction fragments length polymorphism (RFLP) analysis method and DNA sequencing. In this group, the distribution of alleles was as follows: TPMT $* 1 / * 2$, one $* 3 A$ / $* 3 A$, seven $* 1 / * 3 A$ and the remaining 91 were wild type 
$* 1 / * 1$. For the ITPA c.94C $>$ A 12 individuals were heterozygotes, 2 homozygous for the variant allele and the remaining 86 were wild-type homozygous.

Informed consent of the subjects was given in written form. Ethical approval for this study was obtained from the Local Ethical Committee of the University of Medical Sciences in Poznan, Poland (Resolution No. 871/09). DNA was isolated from peripheral blood according to standard procedures using the method with guanidine isothiocyanate (GTC) and stored at $4{ }^{\circ} \mathrm{C}$ in an $\mathrm{AE}$ buffer containing $0.5 \mathrm{mM}$ EDTA and $10 \mathrm{mM}$ Tris-Cl.

\subsection{High Resolution Melting Analysis}

We designed primers to cover c. $238 \mathrm{G}>\mathrm{C}, \mathrm{c} .460 \mathrm{G}>\mathrm{A}$ and c.719A $>\mathrm{G}$ variants of the TPMT gene as well as c.94C $>\mathrm{A}$ of the ITPA gene using Primer3 software. These four primer pairs were combined into two multiplex PCR reactions: fragment c.460G $>A$ with c.719A $>$ G and fragment c. $238 \mathrm{G}>\mathrm{A}$ with c.94C $>$ A. Primer sequences, the concentration used for multiplex PCR and amplicon size are shown in Table 1. The sequence of primers for exon 6 and 9 amplification of the TMPT gene had been published previously [14].

Products were amplified using the Type-it HRM PCR Kit [Qiagen] on a Rotor-Gene Q instrument [Qiagen]. The PCR was performed according to the manufacturer's instructions in a volume of $16 \mu \mathrm{L}$ containing $8 \mu \mathrm{L}$ of $2 \times$ HRM PCR Master Mix, 0.55-2.2 $\mu \mathrm{L}$ of each primer $(5 \mathrm{pmol} / \mu \mathrm{L})$ and $50 \mathrm{ng}$ of DNA. PCR amplification conditions in the four loci were as follows: $95^{\circ} \mathrm{C}$ of pre-incubation for $5 \mathrm{~min}$, followed by 40 cycles of denaturation at $95{ }^{\circ} \mathrm{C}$ for $10 \mathrm{~s}$, annealing for $30 \mathrm{~s}$ at $55^{\circ} \mathrm{C}$ and extension at $72{ }^{\circ} \mathrm{C}$ for $10 \mathrm{~s}$. The HRM analysis was carried out from 70 to $90{ }^{\circ} \mathrm{C}$, raising the temperature by $0.1{ }^{\circ} \mathrm{C}$ degree at each step. Data collection and analysis was performed using Rotor-Gene Software, version 2.0.2. For allele recognition, HRM analyses were done and characteristic curves were visualized in difference graph. The melt normalization ranges for the first amplicon set were as follows: 74.4-74.6 ${ }^{\circ} \mathrm{C}$ and $76.5-76.7{ }^{\circ} \mathrm{C}$ for the fragment covering the position c.719, 77.0-77.3 ${ }^{\circ} \mathrm{C}$ and $79.4-80.2{ }^{\circ} \mathrm{C}$ for fragment corresponding to the position c.460 of the TMPT gene. For the second amplicon set, the melt normalization ranges constituted: $75.8-76.3{ }^{\circ} \mathrm{C}$ and $78.4-78.6{ }^{\circ} \mathrm{C}$ for the fragment with locus c.238 as well as $78.9-79.1{ }^{\circ} \mathrm{C}$ and 80.1-80.3 ${ }^{\circ} \mathrm{C}$ for c.94. The genotypes were identified with at least $99 \%$ confidence.

For the validation of the established assays, analysis of each DNA sample was repeated in three separate runs. During the experiments, for the purpose of validation the DNA samples were blinded.

\subsection{Sequencing of PCR Products}

All polymorphisms detected in HRM were confirmed by direct PCR product sequencing. Selected samples were separately amplified, treated with the QIAquick ${ }^{\mathrm{TM}} \mathrm{PCR}$ Purification Kit (Qiagen, Hilden, Germany) and sequenced bidirectionally on a MegaBACE ${ }^{\mathrm{TM}} 1000$ DNA Analysis System using the DYEnamic ${ }^{\mathrm{TM}}$ ET Dye Terminator Cycle Sequencing Kit (Amersham Biosciences, Buckinghamshire, UK).

\section{Results}

The multiplex HRM analysis of the first primer set for the c. $460 \mathrm{G}>\mathrm{A}$ and c.719A $>\mathrm{G}$ changes in the TPMT gene showed three different melting profiles of exon 9 and five different melting profiles of exon 6 within the entire group studied (Fig. 1). Sequencing the samples representing all three melting profiles revealed the presence of three genotypes $\mathrm{A} / \mathrm{A}, \mathrm{A} / \mathrm{G}$ and $\mathrm{G} / \mathrm{G}$ in position c.719 (Fig. 1b) as well as three genotypes $\mathrm{A} / \mathrm{A}, \mathrm{A} / \mathrm{G}$ and $\mathrm{G} / \mathrm{G}$ in locus c. 460 (Fig. 1c). Two additional profiles were caused by the

Table 1 Primers details and amplicon sizes used in multiplex HRMA

\begin{tabular}{|c|c|c|c|c|c|}
\hline Set no. & Primer name & Gene & Sequence $\left(5^{\prime} \rightarrow 3^{\prime}\right)$ & Amplicon size (bp) & Amount of primers per reaction (pmol) \\
\hline \multirow[t]{4}{*}{1} & Exon6_F & $T P M T$ & TGTTGAAGTACCAGCATGCAC & 173 & 2.75 \\
\hline & Exon6_R & & CTTACCATTTGCGATCACCTG & & 2.75 \\
\hline & Exon9_F & & GAATCCCTGATGTCATTCTTCA & 213 & 11.0 \\
\hline & Exon9_R & & CCTCAAAAACATGTCAGTGTGA & & 11.0 \\
\hline \multirow[t]{4}{*}{2} & Exon4_F & & СССТCTATTTAGTCATTTGAAAACA & 241 & 11.0 \\
\hline & Exon4_R & & AAAACTTTTGTGGGGATATGGA & & 11.0 \\
\hline & Exon2_F & $I T P A$ & TAGGAGATGGGCAGCAGAGT & 163 & 6.75 \\
\hline & Exon2_R & & TCAATTTTCTGTGCCACCAA & & 6.75 \\
\hline
\end{tabular}

HRMA high resolution melting analysis, $F$ forward, $R$ reverse 
polymorphism c.474C $>$ T (rs2842934, p.Ile158Ile), which is found next to the c. $460 \mathrm{G}>\mathrm{A}$. The frequency of $\mathrm{T}$ allele is $24.7 \%$ (dbSNP, 1000 Genomes). It was not possible to design a PCR product for position c. 460 analysis skipping position c.474 of the TMPT gene. Nine combinations of these two variants are possible. We did not observe changed homozygous in both loci, the possibility of their occurrence is low and may be observed approximately in 1 case per 10,000. From our experiment we can assume that the occurrence of the polymorphism does not alter the possibility of the correct identification of genotype in the locus.

Figure 2 presents the results of the melting analysis of PCR products of the second primer set encompassing a c. $238 \mathrm{G}>\mathrm{C}$ change locus of the $T P M T$ gene and c. $94 \mathrm{C}>\mathrm{A}$ of the ITPA gene. For exon 4 of the TPMT gene, a different melting profile was observed once within the group investigated (Fig. 2b), and sequencing of this DNA fragment indicated a heterozygous substitution c. $238 \mathrm{G}>\mathrm{C}$. On the basis of the HRMA of exon 2 of the ITPA gene, three repetitive melting profiles were observed within the entire group (Fig. 2c), and sequencing revealed three corresponding genotypes $\mathrm{T} / \mathrm{T}, \mathrm{T} / \mathrm{C}$, and $\mathrm{C} / \mathrm{C}$ in position c.94.

In terms of the validation all three repeats of the HRM analyses for each sample showed consistent results. Moreover, the genotypes identified with multiplex HRMA for TPMT gene loci c. $238 \mathrm{G}>\mathrm{C}$, c. $460 \mathrm{G}>\mathrm{A}$ and c.719A $>\mathrm{G}$ as well as ITPA gene locus c.94C $>\mathrm{A}$ indicated $100 \%$ accuracy for the whole group compared to the data from RFLP analysis and DNA sequencing. The dropout rate from the established multiplex HRMA was $4.17 \%$ (3 samples per 72), thus staying above our general research mutation screening success rate target of $95 \%$. The optimization was designed to obtain equal peak height of both products in melt profile. Therefore, the PCR containing primer ratios 1:1, 2:1, 3:1 and 4:1 were prepared and analyzed by HRMA. In the next step, primer concentrations, based on analysis of melt profiles, were corrected.

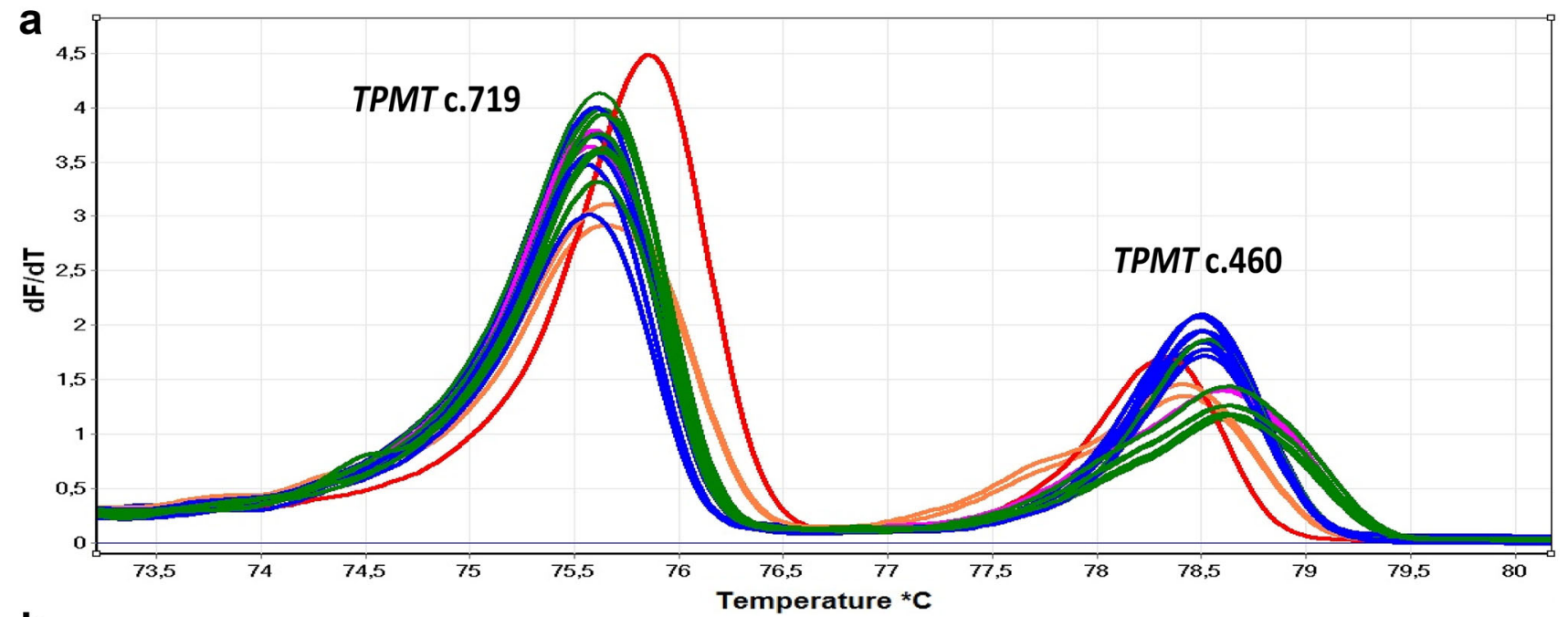

b

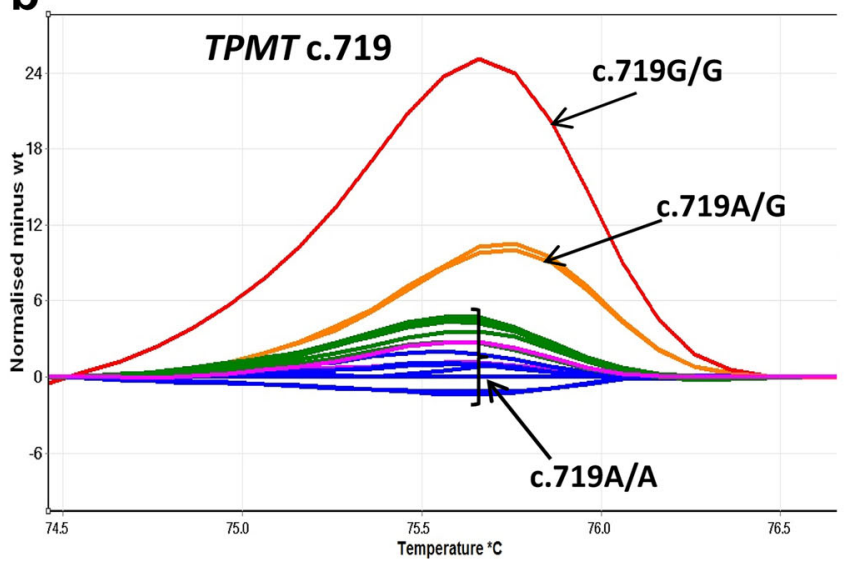

Fig. 1 Multiplex high resolution melting (HRM) analysis for exon 6 and 9 of the TPMT gene. a Melting profile of both polymerase chain reaction (PCR) products. b Normalized difference plots of amplicons

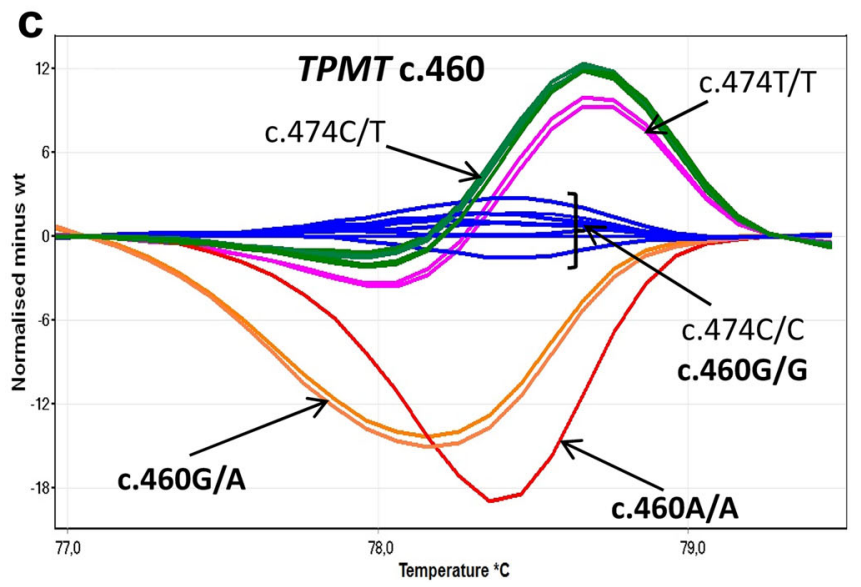

corresponding to exon 9 (c.719). c Normalized difference plots of amplicons corresponding to exon 6 (c.460 and additionally locus c.474) 


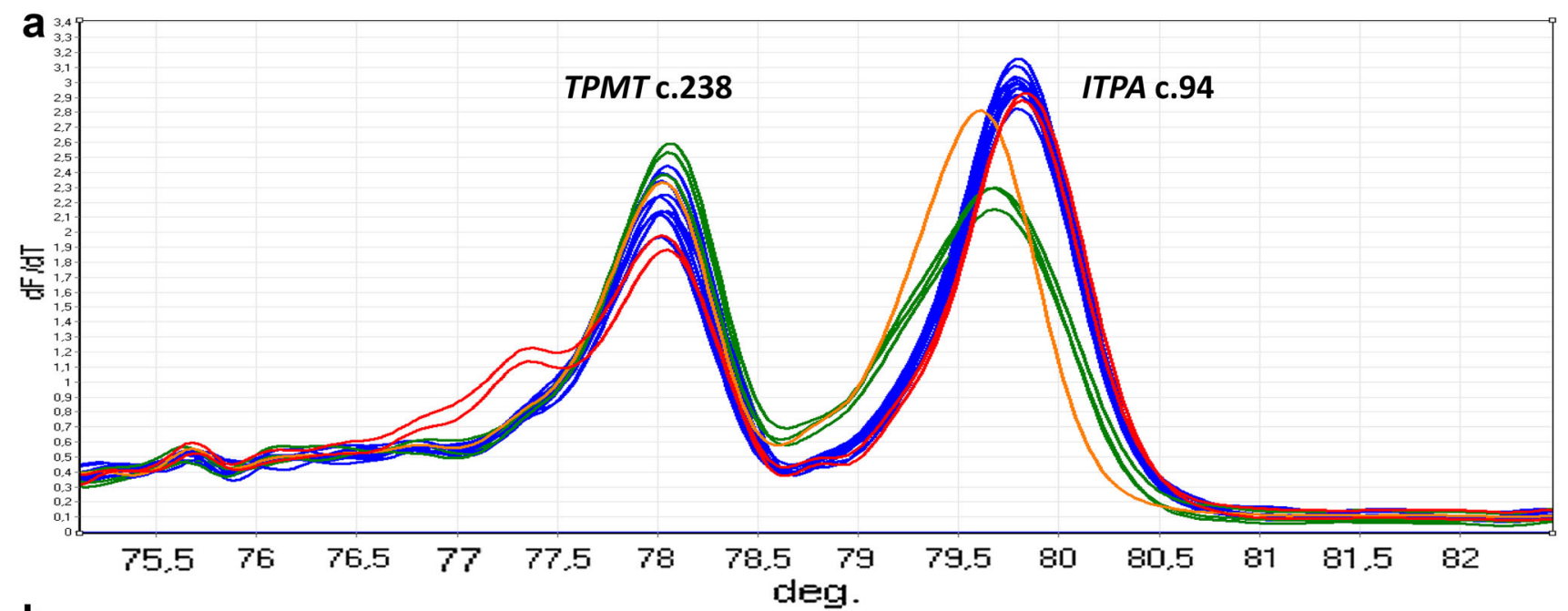

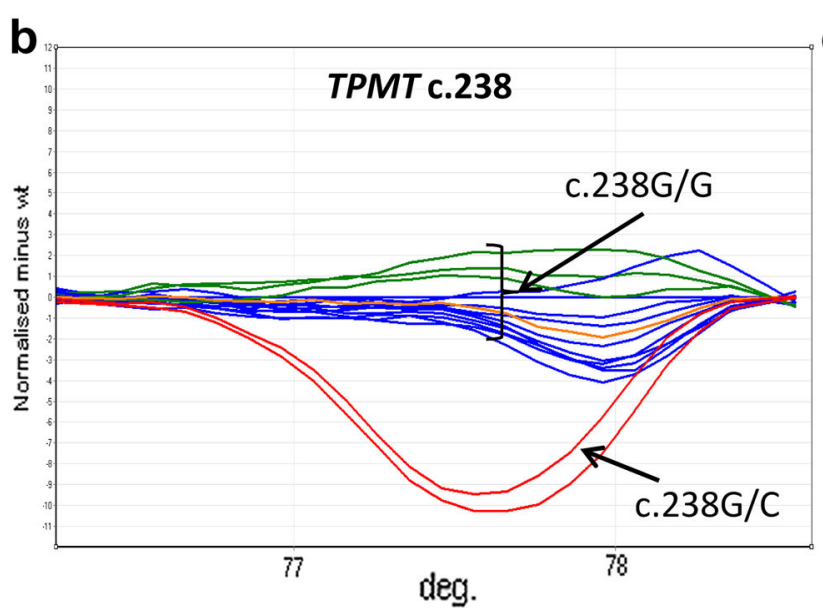

Fig. 2 Multiplex high resolution melting analysis (HRMA) for exon 4 of the TPMT gene and exon 2 of the ITPA gene. a Melting profile of both polymerase chain reaction (PCR) products. b Normalized

The optimization of primer concentration in two runs takes approximately $5 \mathrm{~h}$. For the first multiplex reaction, optimal results were obtained with the primers ratio $4: 1$ and for the second set, ratio 2:1.22 were accepted (Table 1).

\section{Discussion}

For around a decade it has been well established, that the equilibrium between 6MMP and toxic 6TGN in patients undergoing thiopurine drug therapy, depends on the genetic polymorphism of the TPMT and ITPA gene. A strong genotype-phenotype correlation was supported by a number of clinical trials resulting in the development of dosing recommendations for thiopurine drugs based on TPMT genotype. Worldwide the most common inactive alleles are $T P M T * 2$ and $* 3$, and these alleles constitute the basis for pharmacogenetic testing during thiopurine drug treatment $[11-13,15,16]$.
대로.

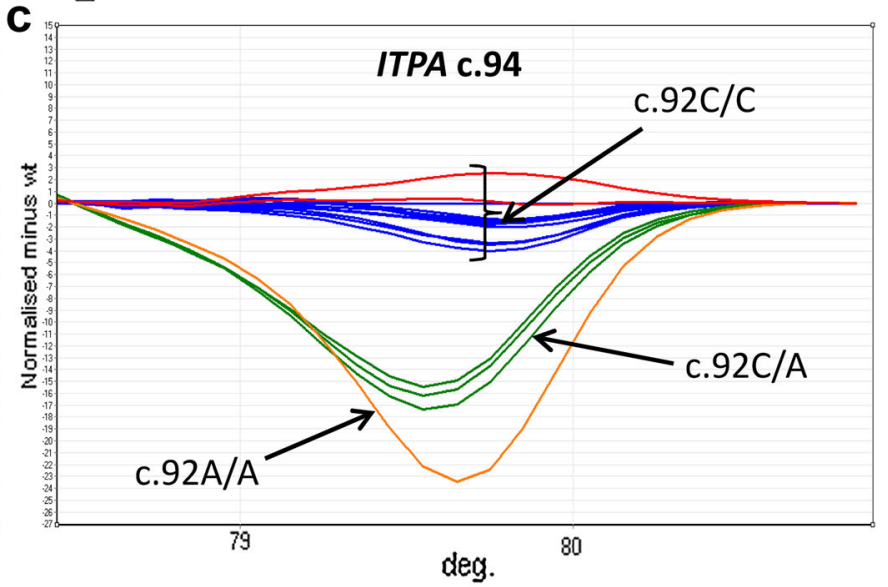

difference plots of amplicons corresponding to exon 4 (c.238). c Normalized difference plots of amplicons corresponding to exon 2 (c.94)

The participation of other genes, ITPA in particular, in adverse reactions and toxic side effects of thiopurines, had been controversial for a long time. In 2004, two mutations resulting in different levels of ITPase-reduced activity were identified: p.P32T (c.94C $>$ A) and IVS2 + 21A $>$ C [17]. Some studies confirmed the importance of only one, c. $94 \mathrm{C}>\mathrm{A}$ [18] or IVS2 $+21 \mathrm{~A}>\mathrm{C}$ [19], of these two ITPA gene changes in predisposition to AZA intolerance. Other investigations showed that none of the ITPA variants had a significant association with renal transplant recipients [20], while in contrast to the above, other researchers suggested the importance of both ITPA substitutions in response to thiopurine treatment and side effects [21]. Finally, in the last five years several independent studies on the large groups of ALL patients, the influence on 6MP metabolism and the toxic effect of multiple loci in the TPMT gene and the variation c.94C $>\mathrm{A}$ in the ITPA gene has been confirmed [9, 22]. Moreover, in research by Smid et al. [10], performed on a group of 408 ALL pediatric patients 
undergoing maintenance therapy with 6MP, the association between one non-functional ITPA allele and the lower risk of suffering early $(p=0.003)$ and/or bone marrow relapse ( $p=0.017$ ) was observed [10]. The authors concluded that the ITPA genotype can be used as a genetic marker for the improvement of survival rate and therapy individualization for patients with ALL [10].

Therefore, we decided to evaluate a quick and cost-effective test for identification of $T P M T 2 *$ and $T P M T * 3$ alleles of TPMT as well as a c.94C $>$ A variant of ITPA by multiplex HRMA. The multiplex real-time PCR for the detection of major TPMT and ITPA alleles is no longer used in the new approach $[11-13,16]$. What is innovative about our test, compared to other real-time PCRs, is its use of HRMA as a more cost-effective and sensitive application, also additionally in a multiplex combination. The advantages of our assay, as a type of real-time PCR analysis, are its high sensitivity, efficiency and lack of an agarose electrophoresis stage compared to standard PCRbased techniques. Moreover, expensive allele-specific fluorescent probes are not necessary and they significantly reduce the costs of the analysis. An estimated cost of HRMA reagents per sample is approximately EUR1.00 and is over two times lower than allele-specific fluorescent probe assay. In the case of RLFP, the reagents have an equivalent cost, but this technique is much more time consuming. The final price per sample for DNA sequencing is about EUR5-6.

For the reliable interpretation of multiplex HRMA results it is crucial to design amplicons with discriminating melting points and a similar efficiency in terms of PCR reactions. We designed PCR products up to 300 base pairs to correct allele discrimination and the melting points of multiplex reactions products differ by at least $2{ }^{\circ} \mathrm{C}$. However, HRM analysis as a screening method has its limitations, all samples with melting profiles different from the wild type should be directly sequenced (or analyzed with the use of a second method) to confirm genotyping results.

The similarity of the PCR products' yield was optimized within sets by proportions of primer pairs. For the first multiplex reaction, a four times greater amount of exon 9 primers relative to the exon 6 of the TPMT gene were used (Table 1). In the second set, optimal results were obtained with a $61.36 \%$ increased amount of exon 4 primers of the TPMT gene relative to the primers of the ITPA gene fragment (Table 1).

\section{Conclusion}

The methodology we describe here allows the simultaneous analysis of c.460G $>A$, c.719A $>\mathrm{G}$ and c. $238 \mathrm{G}>\mathrm{C}$ of the TPMT gene variants, as well as the c.94C $>\mathrm{A}$ of the
ITPA gene by rapid and economic multiplex HRMA. Our results indicated $100 \%$ accuracy for the whole group studied when compared to the data from RFLP and sequencing. Therefore, we conclude that multiplex HRMA can be used as a sensitive and efficient alternative diagnostic method, compared to conventional techniques for genotyping of TPMT*2, TPMT*3 and ITPA c.94C $>\mathrm{A}$ alleles.

Acknowledgments We thank the Polish Ministry of Science and Higher Education (Grant No. N N402209835) for their support.

\section{Compliance with Ethical Standards}

Conflict of interest The authors MSZ, PB, ABK, OZB, MW, AD, $\mathrm{MK}, \mathrm{MW}, \mathrm{DL}, \mathrm{AP}$ and RS declare no conflicts of interest.

Ethical approval and informed consent All patients declared informed consent and the studies were approved by the local Ethics Committee of the Poznan University of Medical Sciences (Approval No. 871/09).

Funding The studies was funded by a Grant from the Polish Ministry of Science and Higher Education (Grant No. N N402209835).

Open Access This article is distributed under the terms of the Creative Commons Attribution-NonCommercial 4.0 International License (http://creativecommons.org/licenses/by-nc/4.0/), which permits any noncommercial use, distribution, and reproduction in any medium, provided you give appropriate credit to the original author(s) and the source, provide a link to the Creative Commons license, and indicate if changes were made.

\section{References}

1. Sahasranaman S, Howard D, Roy S. Clinical pharmacology and pharmacogenetics of thiopurines. Eur J Clin Pharmacol. 2008;64: 753-67. doi:10.1007/s00228-008-0478-6.

2. Lafolie P, Hayder S, Björk O, Ahström L, Liliemark J, Peterson C. Large interindividual variations in the pharmacokinetics of oral 6-mercaptopurine in maintenance therapy of children with acute leukaemia and non-Hodgkin lymphoma. Acta Paediatr Scand. 1986;75(5):797-803.

3. Weinshilboum RM, Sladek SL. Mercaptopurine pharmacogenetics: monogenic inheritance of erythrocyte thiopurine methyltransferase activity. Am J Hum Genet. 1980;32:651-62.

4. Kim HY, Lee SH, Lee MN, Kim JW, Kim YH, Kim MJ, et al. Complete sequence-based screening of TPMT variants in the Korean population. Pharmacogenet Genomics. 2015;25(3): 143-6. doi:10.1097/FPC.0000000000000117.

5. Yates CR, Krynetski EY, Loennechen T, Fessing MY, Tai HL, Pui CH, Relling MV, Evans WE. Molecular diagnosis of thiopurine S-methyltransferase deficiency: genetic basis for azathioprine and mercaptopurine intolerance. Ann Intern Med. 1997;126:608-14.

6. Relling MV, Gardner EE, Sandborn WJ, Schmiegelow K, Pui $\mathrm{CH}$, Yee SW, et al. Clinical pharmacogenetics implementation consortium guidelines for thiopurine methyltransferase genotype and thiopurine dosing: 2013 update. Clin Pharmacol Ther. 2013;93(4):324-5. doi:10.1038/clpt.2013.4.

7. Sumi S, Marinaki AM, Arenas M, Fairbanks L, Shobowale-Bakre M, Rees DC, Thein SL, Ansari A, Sanderson J, De Abreu RA, 
Simmonds HA, Duley JA. Genetic basis of inosine triphosphate pyrophosphohydrolase deficiency. Hum Genet. 2002;111(4-5): 360-7.

8. Marsh S, King CR, Ahluwalia R, McLeod HL. Distribution of ITPA P32T alleles in multiple world populations. J Hum Genet. 2004;49(10):579-81.

9. Adam de Beaumais T, Fakhoury M, Medard Y, Azougagh S, Zhang D, Yakouben K, et al. Determinants of mercaptopurine toxicity in paediatric acute lymphoblastic leukemia maintenance therapy. Br J Clin Pharmacol. 2011;71(4):575-84. doi:10.1111/j. 1365-2125.2010.03867.x.

10. Smid A, Karas-Kuzelicki N, Milek M, Jazbec J, Mlinaric-Rascan I. Association of ITPA genotype with event-free survival and relapse rates in children with acute lymphoblastic leukemia undergoing maintenance therapy. PLoS One. 2014;9(10): e109551. doi:10.1371/journal.pone.0109551.

11. Lorenz M, Weise A, Prause S, Klemm M, Eidens M, Luchi M, et al. Development and validation of a rapid and reliable method for TPMT genotyping using real-time PCR. Clin Lab. 2012;58(9-10):959-71.

12. Kim S, Lee HW, Lee W, Chun S, Min WK. Validation of new allele-specific real-time PCR system for thiopurine methyltransferase genotyping in Korean population. Biomed Res Int. 2013;2013:305704. doi:10.1155/2013/305704.

13. Burchard PR, Abou Tayoun AN, Lefferts JA, Lewis LD, Tsongalis GJ, Cervinski MA. Development of a rapid clinical TPMT genotyping assay. Clin Biochem. 2014;47(15):126-9. doi:10. 1016/j.clinbiochem.2014.07.088.

14. Skrzypczak-Zielinska M, Borun P, Milanowska K, JakubowskaBurek L, Zakerska O, Dobrowolska-Zachwieja A, et al. Highresolution melting analysis of the TPMT gene: a study in the Polish population. Genet Test Mol Biomarkers. 2013;17(2): 153-9. doi:10.1089/gtmb.2012.0192.

15. Román M, Cabaleiro T, Ochoa D, Novalbos J, Chaparro M, Gisbert JP, et al. Validation of a genotyping method for analysis of TPMT polymorphisms. Clin Ther. 2012;34(4):878-84. doi:10. 1016/j.clinthera.2012.02.017.
16. Roberts RL, Barclay ML, Gearry RB, Kennedy MA. A multiplexed allele-specific polymerase chain reaction assay for the detection of common thiopurine S-methyltransferase (TPMT) mutations. Clin Chim Acta. 2004;341(1-2):49-53.

17. Marinaki AM, Duley JA, Arenas M, Ansari A, Sumi S, Lewis $\mathrm{CM}$, et al. Mutation in the ITPA gene predicts intolerance to azathioprine. Nucleosides Nucleotides Nucleic Acids. 2004;23(8-9): 1393-7.

18. von Ahsen N, Armstrong VW, Behrens C, von Tirpitz C, Stallmach $\mathrm{A}$, Herfarth $\mathrm{H}$, et al. Association of inosine triphosphatase $94 \mathrm{C}>\mathrm{A}$ and thiopurine S-methyltransferase deficiency with adverse events and study drop-outs under azathioprine therapy in a prospective Crohn disease study. Clin Chem. 2005;51(12): 2282-8.

19. Hawwa AF, Millership JS, Collier PS, Vandenbroeck K, McCarthy A, Dempsey S, Cairns C, Collins J, Rodgers C, McElnay JC. Pharmacogenomic studies of the anticancer and immunosuppressive thiopurines mercaptopurine and azathioprine. Br J Clin Pharmacol. 2008;66(4):517-28. doi:10.1111/j. 1365-2125.2008.03248.x.

20. Kurzawski M, Dziewanowski K, Lener A, Drozdzik M. TPMT but not ITPA gene polymorphism influences the risk of azathioprine intolerance in renal transplant recipients. Eur J Clin Pharmacol. 2009;65(5):533-40. doi:10.1007/s00228-009-0630-y.

21. Shipkova M, Lorenz K, Oellerich M, Wieland E, von Ahsen N. Measurement of erythrocyte inosine triphosphate pyrophosphohydrolase (ITPA) activity by HPLC and correlation of ITPA genotype-phenotype in a Caucasian population. Clin Chem. 2006;52(2):240-7.

22. Stocco G, Crews KR, Evans WE. Genetic polymorphism of inosine-triphosphate-pyrophosphatase influences mercaptopurine metabolism and toxicity during treatment of acute lymphoblastic leukemia individualized for thiopurine-S-methyl-transferase status. Expert Opin Drug Saf. 2010;9(1):23-37. doi:10.1517/ 14740330903426151. 